\title{
EM BUSCA DA TRANSPARÊNCIA ATIVA EM CÂMARAS: UMA INVESTIGAÇÃO NOS MAIORES MUNICÍPIOS BRASILEIROS
}

\author{
Rodrigo Gondin de Andrade ${ }^{2}$ \\ Fabiano Maury Raupp ${ }^{3}$ \\ José Antonio Gomes de Pinho ${ }^{4}$
}

\begin{abstract}
Resumo: Este estudo investiga a transparência ativa dos portais eletrônicos das câmaras de municípios brasileiros com população superior a duzentos mil habitantes. Trata-se de uma pesquisa descritiva, realizada por meio de um estudo survey, com abordagem qualitativa. Os dados foram coletados mediante análise de 133 portais eletrônicos, registrados utilizando um protocolo de observação. Os resultados contribuem para um diagnóstico situacional dos portais eletrônicos em relação à adequação ou não desses instrumentos à legislação, bem como da presença de outros indicadores que ampliam o conceito de transparência. Conclui-se que a transparência ativa ainda não é uma realidade em câmaras dos maiores municípios brasileiros.
\end{abstract}

Palavras-chave: Câmaras municipais. Transparência ativa. Portais eletrônicos.

\footnotetext{
22E-mail: rodrigondin@gmail.com. Universidade do Estado de Santa Catarina

${ }^{3}$ E-mail: fabianoraupp@hotmail.com. Universidade do Estado de Santa Catarina

${ }^{4}$ E-mail: jagp@ufba.br. Universidade Federal da Bahia
} 


\title{
SEARCHING ACTIVE TRANSPARENCY IN COUNCILS: AN INVESTIGATION IN THE LARGEST BRAZILIAN MUNICIPALITIES
}

\begin{abstract}
This study investigates the active transparency of electronic portals of City Councils in Brazilian municipalities with population greater than two hundred thousand inhabitants. This is a descriptive research, conducted through a survey with qualitative approaches. Data were collected from the analyses of 133 electronic portals, recorded using an observation protocol. The results contribute to a situational diagnostic of the electronic portals regarding the compliance or not of these instruments to the legislation, as well as the presence of other indicators that broaden the concept of transparency. It is concluded that the active transparency is still not a reality in the City Councils of the largest Brazilian municipalities.
\end{abstract}

Keywords: City councils. Active transparency. Electronic portals. 


\section{INTRODUÇÃO}

$A^{\prime}$ reabertura democrática e a promulgação da Constituição Federal de 1988 elevaram o direito de acesso à informação pública ao patamar de direito fundamental, abrindo caminho para o Brasil sancionar a Lei no 12.527 de novembro de 2011, denominada de Lei de Acesso à informação - LAI. O Brasil tornou-se o $89^{\circ}$ país dotado de uma lei de acesso à informação, a qual passou a vigorar no país em maio de 2012, após 180 dias de sua promulgação, conforme previsto no texto da LAI (Angélico, 2012). A LAl inovou o ordenamento jurídico brasileiro ao estabelecer o uso obrigatório de meios eletrônicos, comumente operacionalizados na internet por meio de portais eletrônicos, para a divulgação de um conjunto de informações consideradas essenciais à sociedade, com o objetivo de institucionalizar a "cultura de acesso" na administração pública. São esforços para despertar a consciência de que as informações geridas pela administração pública são de interesse social, cabendo ao Estado a responsabilidade de disponibilizá-las de forma objetiva e compreensível (Jordão, 2011).

Na consolidação da "cultura do acesso" na gestão das organizações públicas, a utilização de meios eletrônicos é parte dos instrumentos do governo eletrônico que ampliam os serviços e disseminam as informações públicas. Tal consolidação requer um modelo de gestão pública capaz de coordenar estratégias e ações para estimular o acesso amplo às informações, promover a responsabilização dos agentes públicos que violarem os dispositivos da LAl e estabelecer programas eficientes de proteção contra a negativa de prestação de informações por parte de órgãos públicos (Michener \& Bersch, 2011; Angélico, 2012; Santos, Bernardes \& Rover, 2012).

Os meios eletrônicos podem contribuir para amenizar as dificuldades existentes na gestão da informação e em questões complexas como é o caso do engajamento social no campo das políticas públicas. Esse potencial configura-se como uma estratégia capaz de aumentar a eficiência e a transparência dos atos dos entes públicos, além de contribuir para efetivar o direito de acesso à informação do cidadão (Fountain, 2001). Para Denhardt (2012), construir possibilidades de engajamento do cidadão no mundo político requer processos multidirecionais de reestruturação das organizações públicas, de modo que se apresentem cada vez mais transparentes. É fato a influência e importância das tecnologias da informação e comunicação - TIC neste sentido, pois consolidam meios para o exercício da transparência das informações e controle social sobre os atos dos atores públicos, o que pode prevenir práticas clientelistas e de corrupção.

Na literatura acadêmica nacional, ainda pouco se sabe sobre o nível de divulgação das informações públicas e sobre os incentivos que afetam essa divulgação. Portanto, estudos científicos sobre o tema representam uma oportunidade de contribuição para a realidade do setor público (Bairral, Silva \& Alves, 2015). Tal contexto incentiva pesquisas que possam identificar os possíveis impactos dos portais eletrônicos como instrumentos para potencializar a transparência. Considerando que estudos desta natureza normalmente ocorrem com o executivo (Raupp, 2011), busca-se, de modo particular, resposta para a seguinte pergunta de pesquisa: Em que medida os portais eletrônicos de câmaras localizadas em municípios brasileiros com população superior a duzentos mil habitantes possibilitam a construção da transparência ativa? Neste sentido, tem-se como objetivo investigar a transparência ativa de câmaras localizadas em municípios brasileiros com população superior a duzentos mil habitantes a partir de evidências empíricas dos portais eletrônicos. $\mathrm{O}$ artigo está organizado em cinco seções, iniciando por esta introdução. Na sequência é apresentado o referencial teórico que se entende necessário para dar 
suporte ao objeto empírico. A terceira seção contempla os procedimentos metodológicos adotados. As próximas seções discorrem, respectivamente, sobre os achados da pesquisa e as conclusões.

\section{FUNDAMENTOS TEÓRICOS}

\subsection{ACCOUNTABILITY}

O referencial teórico contempla os conceitos de accountability, transparência e governo eletrônico, considerados necessários para dar sustentação ao objeto empírico. Em relação ao conceito, a dificuldade que envolve uma definição objetiva para o conceito de accountability decorre da relação entre poder e sistema de governança de um Estado. Esta relação pode ser sintetizada na seguinte proposição "em política, primeiro vem o poder e depois a necessidade de controlá-lo" (Schedler, Diamond \& Plattner, 1999, p.13). O termo representa a preocupação com temas como transparência, fiscalização, controle sobre o exercício do poder e responsabilização. Por ser um conceito relativamente novo, a accountability ainda possui o seu significado evasivo e confuso (Pinho \& Sacramento, 2009). Para Koppell (2005), o significado aparece em alguns artigos como controle da burocracia, já em outros significa transparência. Em outros é utilizado como sinônimo de respeito e aderência às leis, ou ainda, como responsividade às demandas do cidadão (Koppell, 2005).

Para Schedler, Diamond e Plattner (1999), o conceito de accountability considera dois fundamentos básicos: (1) answerability que diz respeito à obrigação dos gestores públicos em serem transparentes, ou seja, informar e justificar as razões das suas ações; e (2) enforcement que corresponde a capacidade de impor sansões aos gestores públicos que não cumprirem com as suas obrigações. Accountability como answerability demanda publicidade e justificativas das ações públicas ao cidadão, só assim a perspectiva informacional poderá criar condições de transparência dos atos públicos. Aos elementos informacionais, que devem contemplar a transparência do que foi feito, do que está sendo feito e do que será feito, são acrescidos elementos regulatórios que consideram sanções e incentivos (enforcements). Portanto, a responsabilidade não está apenas em publicizar o que está sendo feito e apresentar justificativas, mas também assumir eventuais sanções (Schedler, Diamond \& Plattner, 1999; Denhardt, 2012).

A abordagem da accountability que segue a lógica de answerability e enforcement é encontrada na proposta do Novo Serviço Público - NSP de Denhardt e Denhardt (2007). Na ótica do NSP existem cinco dimensões distintas de accountability: a primeira diz respeito à transparência, e questiona se a organização revelou os fatos de sua performance; a segunda dimensão é a da imputabilidade, que implica em saber se a organização sofreu as consequências decorrentes da sua performance; a terceira dimensão consiste na controlabilidade, e questiona se a organização realizou as determinações dos seus superiores, ou seja, a quem ela deve prestar contas; a quarta dimensão, por sua vez, refere-se à responsabilidade e consiste em responder se a organização seguiu as regras; por último, a quinta dimensão diz respeito à responsividade, isto é, se a organização atendeu a expectativa substantiva que deveria (Koppel, 2005; Denhardt, 2012). As dimensões propostas não são mutuamente exclusivas, o que significa que as organizações podem ser accountable em mais de um sentido. Dentre as dimensões identificadas, o estudo destaca a dimensão transparência, por ser considerada um dos alicerces de accountability, isto quer dizer sustenta o conceito em todas as suas formas de manifestações (Koppell, 2005), mas também em razão do objeto empírico considerado. 
O conceito de transparência tem atraído atenção, conforme Michener e Bersch (2011), pois congrega ambivalência e uma carga normativa positiva. Mesmo inspirando diversas frases inteligentes de definição e adjetivos a partir de volumosas pesquisas, essa ebulição acadêmica não tem sido sustentada por uma compreensão coletiva do que seja transparência, e muito menos qualquer debate acerca de parâmetros para o que a constitui e o que a não constitui. Essa ausência de parâmetros, e a consequentemente confusão no emprego do conceito podem reduzir a sua utilidade (Swartz, 2010; Michener \& Bersch, 2011). Mesmo diante de uma amplitude que pode gerar confusões conceituais, duas questões necessariamente devem ser relacionadas ao conceito: a visibilidade (visibility) e a inferência (inferability). A primeira refere-se ao grau do conteúdo da informação e a facilidade de encontrá-lo. Já a segunda relaciona-se ao grau com que a informação possa ser utilizar para gerar considerações verificáveis (Michener \& Bersch, 2011).

O conceito de transparência não deve se restringir às obrigações legais de tornar disponíveis à sociedade determinados tipos de informação. Deve ir além, ou seja, constituir-se em um meio para o cidadão fique mais engajado nas questões públicas. O exercício de transparência em um sentido ampliado (que considera elementos não restritos às exigências legais) pode, inclusive, contribuir para a criação de condições de construção de accountability, aprimoramento da qualidade de programas públicos e de criação de uma sociedade bem informada e ativa (Denhardt \& Denhardt, 2007; Bass \& Moulton, 2010; Denhardt, 2012). O cidadão passa a coproduzir bens e serviços ao lado do Estado, sendo possivelmente responsável por trazer inputs às ações governamentais (Denhardt \& Denhardt, 2007; Noveck, 2009; Bass \& Moulton, 2010; Fung \& Weil, 2010). O contorno mais amplo no conceito de transparência considera a obrigação moral de publicizar toda informação de interesse público. $O$ agente público deve receber sanções nos casos de não disponibilizar informações de interesse público. A dimensão imputabilidade relaciona a culpabilidade à transparência, e os servidores públicos e as organizações devem ser responsabilizados por suas ações, punidos por prevaricação, e recompensado pelo sucesso (Koppell, 2005), ações que conectam o conceito de transparência ao conceito de accountability.

\subsection{PROCURANDO PELA ACCOUNTABILITY NA REALIDADE BRASILEIRA}

No resgate das primeiras inserções do termo accountability na realidade brasileira, quando o termo entra no léxico brasileiro, o relato de Campos (1990) é inevitável. Quando foi fazer o seu Mestrado nos EUA, ainda nos anos 1970, se deparou com o uso constante do termo, o qual não conhecia e nem fazia ideia do que se tratava. Ao tomar conhecimento percebeu que não havia uma tradução para o idioma Português. Não havia uma única palavra que expressasse o que era dito no idioma e na situação anglo-saxônica. À medida que se aprofundava no exame do termo percebia que o que nos faltava não era o termo em si, mas o conceito (Campos, 1990). Nota-se que Heloísa Buarque de Almeida ao fazer a tradução de um texto do Inglês de autoria de Marilyn Strathener para o Português, no ano de 1999, se deparou com o mesmo termo e que, ao que tudo indica não conhecedora do artigo de Campos (1990), buscou traduzir o termo, mas mostrou dificuldades, pois precisou recorrer a dois termos:"responsabilidade" e "prestação de contas" para exprimir o que os anglofônicos precisavam de apenas uma palavra (Strathern, 1999, p. 16). Por isso, que a melhor solução ao ter que se usar o termo accountability em Português seja deixá-lo em sua língua original.

Campos (1990) avança no sentido de identificar o que faltava para o termo accountability ter guarida na situação brasileira. Neste sentido identificou que nos faltava uma sociedade civil ativa, participativa, enquanto se tinha um Estado tutelador. Pinho e Sacramento (2009), passados vinte anos da experi- 
ência relatada por Campos (1990), voltaram a examinar a situação na primeira década dos anos 2000, inquirindo se, afinal, já seria possível traduzir o termo para o idioma nacional. Os autores constataram avanços, principalmente institucionalizados através de instituições e leis, mas ainda estávamos longe de encontrar um termo que expressasse tudo o que em inglês uma palavra resumia. Ao que parece os autores queriam dizer que ainda não tínhamos o conceito. Assim, ainda que brevemente, vale a pena ver os requisitos estampados por Campos (1990) para ver as perspectivas que podem ser alimentadas. Seguindo uma interpretação weberiana, "o nosso atraso"é visto como"resultante de um vício de origem, em razão do tipo de colonização a que fomos sujeitos, a chamada herança do patrimonialismo ibérico" (Vianna, 1999, p. 35). Ainda que isto tenha se dado no início da colonização, essas "estruturas teriam sido ainda mais reforçadas com o transplante, no começo do século XIX, do Estado português no solo americano" (Vianna, 1999, p. 35). Disto resulta um “Estado duramente autônomo em relação à sociedade civil, que, ao abafar o mundo dos interesses privados e inibir a livre-iniciativa, teria comprometido a história das instituições com concepções organicistas" (Vianna, 1999, p. 35). Uma das marcas mais fortes e características deste arranjo encontra-se na não observância de "fronteiras nítidas a demarcar as atividades das esferas pública e privada". (Vianna, 1999, p. 35). Essa situação também se revela no fato de que no Brasil "o Estado, por anteceder aos grupos de interesse, mais do que autônomo em face da sociedade civil, estaria empenhado na realização de objetivos próprios aos seus dirigentes, enquanto a administração pública, vista como um bem em si mesmo, é convertida em um patrimônio a ser explorado por eles" (Vianna, 1999, p. 35). Se o Estado e a administração pública são assim, do outro lado, a sociedade é presa de "um sistema político de cooptação sobreposto ao de representação" onde circula um "indivíduo como um ser desprovido de iniciativa e sem direitos diante do Estado".

Ao se reconhecer esse diagnóstico, percebe-se que a constatação de Campos (1990), reiterada por Pinho e Sacramento (2009), tinha razão de ser. A nossa trajetória histórica, por outro lado, foi incapaz de romper com essa situação, ainda mais por estarmos ancorados em um capitalismo que seria "politicamente orientado" mostrando-se "uma modalidade patológica de acesso ao moderno, implicando uma modernização sem prévia ruptura com o passado patrimonial" (Vianna, 1999, p. 36) e onde "as elites identificadas com ele deteriam o controle político do processo de mudança social". Nessa construção histórica como podemos ver não há espaço para accountability, para sociedade civil ativa ou protagonista, ou esta tem que ser construída, extraída a fórceps das elites políticas. “[...] a pré-condição [precondição] mais importante para que um sistema de accountability realmente funcione é a atividade dos cidadãos nos fóruns públicos democráticos e na sociedade civil" (Arato, 2002, p. 103). Se o autor coloca essas palavras como alerta para sociedades mais maduras, isto se torna mais necessário ainda para a situação brasileira, conforme descrito acima. A construção da base teórica serve como um guia, um referencial para o exame do objeto empírico. A existência de fenômenos estruturados e perenes na realidade brasileira mostra os limites da tecnologia para mudar esta situação.

\subsection{TRANSPARÊNCIA}

Mesmo entendendo que o conceito de transparência deva ir além de questões legais, Bairral, Silva e Alvez (2015) relatam que o tema da transparência pública ganhou maior relevância, no Brasil, a partir da Lei de Responsabilidade Fiscal (BRASIL, 2000), e, desde então, normativos legais como a Lei da Transparência (BRASIL, 2009) e a Lei de Acesso à Informação (BRASIL, 2011) iniciaram um ciclo de mudanças na relação cidadão/gestor público. Para os autores, estas leis determinaram a divulgação, 
e não o sigilo, como norma geral para a informação pública, envolvendo o fornecimento de dados em uma linguagem acessível e sem barreiras técnicas. Koppell (2005) entende que um ente público é transparente quando garante a eficácia das leis de acesso à informação e disponibiliza acesso sobre seu desempenho aos interessados em suas atividades. No caso brasileiro, a promulgação da Constituição Federal de 1988 estabeleceu as bases legais do direito de acesso à informação pública no Brasil, previstas no art. 5०, XXXIII, ao regulamentar que "todos têm direito a receber dos órgãos públicos informações de seu interesse particular, ou de interesse coletivo ou geral, que serão prestadas no prazo da lei, sob pena de responsabilidade, ressalvadas aquelas cujo sigilo seja imprescindível à segurança da sociedade e do Estado". Até a promulgação da LAI em 18 de novembro de 2011 que regulamenta o direito de acesso à informação previsto no inciso XXXIII do art. $5^{\circ}$, no inciso II do $\S 3^{\circ}$ do art. 37 e no $\S 2^{\circ}$ do art. 216 da Constituição Federal, este direito não estava regulamentado na sociedade brasileira. Estava disposto apenas como princípio geral na Constituição Federal de 1988 e em convenções e declarações internacionais assinadas pelo Brasil, como, por exemplo, a Declaração Interamericana de Princípios de Liberdade de Expressão.

A LAl é um importante avanço para o desenvolvimento da transparência, evidentemente de duas formas: transparência ativa e transparência passiva. A primeira dimensão impõe aos órgãos e entidades públicas, de todos os poderes, o dever de publicar em local de fácil acesso e por meio da internet, as informações produzidas e mantidas por eles. A segunda dimensão exige que os órgãos e entidades da administração pública forneçam repostas e informações aos pedidos formulados pelos cidadãos, seja via internet ou presencialmente, em prazo não superior a 20 dias, que poderá ser prorrogado por mais 10 dias, mediante justificativa expressa (Ferreira et al., 2014). A transparência ativa implica em uma postura proativa e espontânea dos gestores públicos em publicar um conjunto de informações consideradas de interesse público. Um caminho para avaliar a transparência ativa é verificar empiricamente se os órgão e entidades estão divulgando espontaneamente um conjunto mínimo de informações determinadas pela LAl: estrutura organizacional, endereços e telefones; registro de informações orçamentárias como os repasses, transferências e despesas; dados das licitações, acesso aos editais e divulgação dos resultados e dos contratos; dados gerais de programas, ações, projetos e obras; registro das respostas às perguntas mais frequentes da sociedade; formulário eletrônico para solicitação de informação; $\mathrm{e}$ divulgação de relatórios em formato aberto (BRASIL, 2011).

A despeito dos avanços possibilitados pela LAl, o advento de obrigações legais não é o que garante maior grau de democracia, contexto que depende de informações publicadas com conteúdo completo e, principalmente, do uso que é feito delas pelos cidadãos (Bass \& Moulton, 2010; Santos, Bernardes\& Rover, 2012). São muitos os desafios que estão colocados à frente de um governo que busca consolidar na prática o direito de acesso à informação. Entre esses desafios há a falta de divulgação dos direitos previstos na LAl e suas sanções (art. 32, 33 e 34 da LAl); a inexistência de um órgão exclusivamente dedicado ao direito de acesso à informação; o baixo nível de sanções aplicadas pelo descumprimento da LAl; a fraca atuação da sociedade civil; enormes volumes de requerimentos relacionados à pedidos de informação pública; solicitações ambivalentes ou excessivamente amplas (Michener \& Bersch, 2011; Angélico, 2012). Ressalta-se que a inexistência de um órgão central que fiscalize e regule a implementação e o cumprimento da LAI reforça a necessidade da participação e monitoramento por parte da sociedade em relação à efetivação do direito à informação, o que é facilitado mediante o uso estratégico das TIC (Ferreira et al., 2014). O poder de coerção (enforcement) fornece mais estímulos para a divulga- 
ção, principalmente em países onde os "oficiais do governo não agem necessariamente de acordo com a sua responsabilidade, mas sim quando forçados por uma obrigação legal (Michener \& Bersch, 2011).

\subsection{GOVERNO ELETRÔNICO}

A relação entre os conceitos já apresentados, accountability e transparência, com o conceito de governo eletrônico, que complementa a construção teórica do estudo, considera que a accountability depende da configuração de um conjunto de condições que se complementam e se reforçam, e de que a publicidade das contas públicas não pode ser assumida como efetiva transparência por parte dos governos (Prado, 2004). Da mesma forma, conforme Prado (2004) é prematura a afirmação, muito frequente na literatura, de que a implantação de um programa de governo eletrônico leve necessariamente a um aumento de transparência e, consequentemente, de accountability. Ainda que o governo eletrônico represente um potencial importante, com efeitos positivos sobre a transparência e a accountability, depende da existência de mecanismos institucionais para sua efetivação. O conceito de governo eletrônico surge em meio a um contexto amplo, caracterizado de um lado pelos movimentos de reforma do Estado e emergência de temas como accountability e transparência e, de outro, pelo surgimento de novas tecnologias na área da informática que permitiram a criação de sistemas de informação mais abrangentes, assim como o desenvolvimento vertiginoso da microinformática e da internet (Prado, 2004). Temas como accountability e transparência, relacionados à modernização da gestão pública, foram associados ao processo de construção de programas de governo eletrônico. $O$ desdobramento desses temas em políticas públicas e iniciativas concretas requerem o uso de tecnologia, tornando os programas de governo eletrônico elementos potencializadores de novos patamares de eficiência da administração pública (Diniz et al., 2009).

O governo eletrônico, que não deve ser visto apenas por meio da disponibilização de serviços on-line, mas, também, pela gama de possibilidades de interação e participação entre governo e sociedade e pelo compromisso de transparência por parte dos governos (Pinho, 2008). Para o autor, o conceito de governo eletrônico considera duas frentes interconectadas: por um lado, um Estado mais responsivo, aberto à participação da sociedade e transparente e, por outro, considera um papel protagonista da sociedade civil, atribuindo a essas possibilidades, por intermédio dos cidadãos e/ou de movimentos sociais, de checar, aferir, controlar o governo e, ainda, de assumir um papel propositivo. Tais considerações estão profundamente imbricadas à questão da transparência, o que demanda não só um papel democrático do governo, mas, também, uma capacidade política da sociedade civil. O desenvolvimento do governo eletrônico tem como base a utilização de TIC para democratizar o acesso à informação e aperfeiçoar a prestação de serviços públicos pelo aumento da eficiência e eficácia das atividades governamentais. Perspectivas mais recentes, indicam que por meio do governo eletrônico é possível aprimorar as relações entre o governo, os cidadãos, as organizações e órgãos do próprio governo (Prado et al., 2011).

Barbosa (2014) destaca a intensiva adoção das TIC por parte dos órgãos governamentais para apoiar a estruturação dos programas de governo eletrônico, que surgem para fomentar a modernização da administração pública. Conforme o autor é cada vez mais difundida entre os gestores públicos a percepção de que essas políticas públicas podem gerar impactos positivos nas dimensões econômica, social e política e favorecer o melhor desempenho da organização governamental e maior interação entre o setor público e a sociedade. A ideia de modernização da administração pública pode ser traduzida pela busca de aumento da eficiência dos processos internos de governo, melhoria da qualidade 
dos serviços públicos, redução de custos, aumento da produtividade dos servidores, transparência e controle social (Barbosa, 2014). O governo eletrônico deve ser um potencializador de boas práticas de governança e catalisador de uma mudança profunda nas estruturas de governo, proporcionando mais eficiência, transparência e desenvolvimento, além do provimento democrático de informações para decisão (Ruediger, 2002). Esses desafios são decorrentes da necessidade do gestor público lidar com os enormes volumes de informações que precisam ser armazenadas e publicadas, a velocidade com que os conteúdos se transformam e as mudanças nas estruturas de trabalho e nas relações entre governo e sociedade resultantes das inovações tecnológicas. Novos meios de comunicação e de colaboração são necessários para a superação desses desafios (Terra\& Gordon, 2002). Uma forma central dessa informatização tem sido a construção de portais governamentais, por intermédio dos quais os governos mostram sua identidade, seus propósitos, suas realizações, possibilitam a concentração e disponibilização de serviços e informações, o que facilita a realização de negócios e o acesso à identificação das necessidades dos cidadãos. Não se esgotam nesses elementos, no entanto, os objetivos dos governos eletrônicos, também incluindo outros referentes ao aumento da transparência e participação da sociedade nas ações governamentais (Pinho, 2008). Diante disso, os portais eletrônicos representam uma importante ferramenta estratégica para a administração pública gerir as informações com velocidade, precisão e envolvimento dos cidadãos com custos relativamente baixos (Terra\& Gordon, 2002). O portal eletrônico representa uma interface individualizada e disponibilizada na internet em tempo integral que se constitui em um ponto de acesso a recursos de informação e conhecimento de uma instituição e, também, de seus serviços (Dias, 2001; Akutsu \& Pinho, 2002). É possível por meio desses canais de comunicação operacionalizar o que determina o art. $8^{\circ}$ da LAl: "é dever dos órgãos e entidades públicas promover, independente de requerimentos, a divulgação em local de fácil acesso, no âmbito de suas competências, de informações de interesse coletivo ou geral por eles produzidas e custodiadas" (BRASIL, 2011).

\section{PERCURSO METODOLÓGICO}

A pesquisa realizada é classificada como de natureza descritiva, que possui como objetivo a descrição das características de determinada população e suas variáveis. Uma das características mais significativas da pesquisa descritiva está na utilização de técnicas padronizadas de coleta de dados, por exemplo, a observação sistemática (Gil, 2002). Esta pesquisa pode ser caracterizada também como um estudo de levantamento, que busca descrever ou explicar as características de uma população, utilizando uma amostra representativa. É particularmente relevante ao permitir o teste de proposições complexas que envolvem diversas variáveis em interação simultânea (Babbie, 1999). No tocante à abordagem do problema, este estudo adota abordagem qualitativa. Creswell (2007) observa que a investigação qualitativa emprega diferentes alegações de conhecimento, estratégias de investigação e métodos de coleta e análise de dados e o método quantitativo emprega instrumentos estatísticos como base no processo de análise de um problema, bem como há intenção de medir unidades ou categorias homogêneas.

Optou-se por investigar os portais de câmaras localizadas em municípios brasileiros com população superior a duzentos mil habitantes, por considerar que as cidades com esse porte possuem melhores condições técnicas e financeiras para o desenvolvimento e estruturação de portais eletrônicos. Pressupõe-se também que quanto maior a população, maior é a necessidade do uso de portais eletrônicos na comunicação e interação entre governo e sociedade, pois o contato com os parlamentares em cidades maiores é mais digital do que presencial, e as informações que seriam apresentadas aos 
cidadãos presencialmente, passam a ser veiculadas no meio digital (Raupp \& Pinho, 2013). Municípios maiores e mais populosos tendem a publicar maior quantidade de informações da gestão municipal à sociedade, devido à pressão da sociedade para que a gestão pública municipal justifique seus atos (Styles \& Tennyson, 2007).

O porte populacional foi obtido junto ao Censo Demográfico 2010 do Instituto Brasileiro de Geografia e Estatística (IBGE). Já os endereços eletrônicos dos portais das Câmaras Municipais foram obtidos a partir de pesquisas no site Google, realizadas nos dias 22 e 23 de janeiro de 2014. Identificou-se 133 municípios com população superior a duzentos mil habitantes, conforme distribuição por regiões e estados desenvolvida na Tabela 1.

Tabela 1: Municípios por regiões e estados

\begin{tabular}{|c|c|c|c|}
\hline \multirow{2}{*}{ Regiões } & \multirow{2}{*}{ Estados } & \multicolumn{2}{|c|}{ Municípios } \\
\hline & & n. ${ }^{\circ}$ & $\%$ \\
\hline \multirow{7}{*}{ Norte } & Pará & 4 & \multirow{7}{*}{7,52} \\
\hline & Roraima & 1 & \\
\hline & Tocantins & 1 & \\
\hline & Amazonas & 1 & \\
\hline & Acre & 1 & \\
\hline & Amapá & 1 & \\
\hline & Rondônia & 1 & \\
\hline \multirow{9}{*}{ Nordeste } & Sergipe & 1 & \multirow{9}{*}{19,55} \\
\hline & Alagoas & 2 & \\
\hline & Bahia & 5 & \\
\hline & Paraíba & 2 & \\
\hline & Pernambuco & 6 & \\
\hline & Ceará & 4 & \\
\hline & Rio Grande do Norte & 3 & \\
\hline & Maranhão & 2 & \\
\hline & Piauí & 1 & \\
\hline \multirow{4}{*}{ Centro Oeste } & Goiás & 3 & \multirow{4}{*}{5,26} \\
\hline & Distrito Federal & 1 & \\
\hline & Mato Grosso & 2 & \\
\hline & Mato Grosso do Sul & 1 & \\
\hline \multirow{4}{*}{ Sudeste } & São Paulo & 39 & \multirow{4}{*}{51,88} \\
\hline & Rio de Janeiro & 13 & \\
\hline & Minas Gerais & 13 & \\
\hline & Espírito Santo & 4 & \\
\hline \multirow{3}{*}{ Sul } & Santa Catarina & 4 & \multirow{3}{*}{15,79} \\
\hline & Rio Grande do Sul & 9 & \\
\hline & Paraná & 8 & \\
\hline \multicolumn{2}{|c|}{ Total } & 133 & 100,00 \\
\hline
\end{tabular}

Em um balanço por região, são 10 municípios da região Norte, 26 da região Nordeste, 21 da região Sul, 69 da região Sudeste e 7 da região Centro-Oeste. Esse conjunto dá um mosaico praticamente de todo o País, evidentemente com mais ênfase e participação de municípios do Sudeste (51,88\%), onde a urbanização se dá de forma mais intensa, mas não deixa de cobrir todas as regiões.

Creswell (2007) recomenda em estudos com observações múltiplas, como é o caso da presente pesquisa, o uso de um protocolo de observação para registrar as informações consideradas relevantes. Para tanto, elaborou-se um protocolo observacional com dois grupos de indicadores de transparên- 
cia ativa: o primeiro grupo foi elaborado com base nas diretrizes da LAl; o segundo grupo considera instrumentos de transparência não restritos às exigências legais. $O$ protocolo guiou a coleta de dados nos portais realizada no mês de junho de 2014. Assim, à medida que as visitas eram realizadas, as informações julgadas pertinentes eram registradas no protocolo. A definição de um mês de coleta foi feita no sentido de dar equidade ao levantamento de dados, todos coletados em um mesmo mês. Ambos os grupos de indicadores são descritos no Quadro 1.

Quadro 1: Indicadores de transparência ativa

\begin{tabular}{|c|}
\hline 1. Restritos às exigências legais \\
\hline $\begin{array}{l}\text { 1.1 Registros das competências e estrutura organizacional, endereços e telefones das respectivas unidades e horários de } \\
\text { atendimento ao público (Art. } 8^{\circ}, \S 1^{\circ}, \mathrm{I} \text { da LAI). }\end{array}$ \\
\hline 1.2 Registros de quaisquer repasses ou transferências financeiras (Art. $8^{\circ}, \S 1^{\circ}, \mathrm{Il}$, da LAI). \\
\hline Registros das despesas (Art. $8^{\circ}, \S 1^{\circ}, \mathrm{III}$, da LAI). \\
\hline $\begin{array}{l}\text { 1.3 Disponibilidade de informações concernentes a procedimentos licitatórios, inclusive os respectivos editais e resultados, bem } \\
\text { como a todos os contratos celebrados (Art. } 8^{\circ}, \S 1^{\circ}, \mathrm{IV} \text {, da LAI). }\end{array}$ \\
\hline $\begin{array}{c}\text { 1.4 Registros de dados gerais para o acompanhamento de programas, ações, projetos e obras (link de notícias) (Art. } 8^{\circ}, \S 1^{\circ}, \mathrm{V}, \text { dal }^{\circ} \\
\text {. }\end{array}$ \\
\hline 1.5 Registros das respostas às perguntas mais frequentes (Art. $8^{\circ}, \S 1^{\circ}, \mathrm{VI}$, da LAl). \\
\hline Possibilidade de qualquer interessado apresentar pedido de informações por meio de formulário eletrônico (Art. 10, $\$ 2^{\circ}$, da LAI). \\
\hline $\begin{array}{c}\text { 1.6 Disponibilidade de link específico de transparência que dará acesso às informações de interesso público (Art. } 7^{\circ}, \S 2^{\circ}, 1 \text {, do } \\
\text { Decreto no } 7.724 \text { de 2012). }\end{array}$ \\
\hline $\begin{array}{l}\text { 1.7 Registros de remuneração e subsídios (dos vereadores, servidores e funcionários comissionados) (Art. 7º, § 3, Vl, do Decreto } \\
n^{\circ} 7.724 \text { de 2012). }\end{array}$ \\
\hline $\begin{array}{l}\text { 1.8 Possibilidade de upload de relatórios em diversos formatos eletrônicos, inclusive abertos, tais como planilhas e texto, de } \\
\text { modo a facilitar a análise das informações (Art. } 8^{\circ}, \S 3^{\circ}, \mathrm{II} \text {, da LAI). }\end{array}$ \\
\hline 2. Não restritos às exigências legais \\
\hline 2.1 Possibilidade de upload dos vídeos das sessões legislativas ou programas (TV Câmara). \\
\hline 2.2 Disponibilidade de Home Page, Facebook ou twitter dos vereadores (link). \\
\hline 2.3 Disponibilidade de e-mail ou telefone dos vereadores. \\
\hline 2.4 Disponibilidade de legislação municipal. \\
\hline 2.5 Registros de detalhamento das sessões legislativas. \\
\hline 2.6 Possibilidade de encontrar os Projetos de Lei propostos pelos vereadores. \\
\hline 2.7 Possibilidade de acompanhar os Projetos de Lei em suas fases de tramitação. \\
\hline 2.8 Registros de comissões existentes. \\
\hline
\end{tabular}

Os indicadores descritos no Quadro 1 subsidiaram a análise da adequação dos portais eletrônicos às exigências legais, bem como a instrumentos não restritos às exigências legais. Os indicadores descritos na parte 1 foram identificados na LAl e no Decreto no 7.724, de 16 de maio de 2012. Os indicadores elencados na parte 2 e o modelo de análise apresentado do Quadro 2 foram adotados do estudo de Raupp (2011), por tratar-se de um instrumento elaborado a partir da observação empírica de portais eletrônicos e de outros modelos de análise de pesquisas na área de portais.

Quadro 2: Modelo de análise

\begin{tabular}{|c|c|}
\hline Capacidade & Indicadores \\
\hline Nula & Inexistência de indicadores de transparência ativa ou impossibilidade de localização \\
\hline Baixa & Atendimento parcial aos indicadores legais de transparência ativa \\
\hline Média & Atendimento integral aos indicadores legais de transparência ativa \\
\hline Alta & $\begin{array}{c}\text { Atendimento integral aos indicadores legais de transparência ativa e disponibilização de } \\
\text { indicadores de transparência ativa não restritos às exigências legais }\end{array}$ \\
\hline
\end{tabular}

Fonte: Adaptado de Raupp (2011).

Conforme descrito no Quadro 2, a capacidade dos portais poderá receber a seguinte classificação: (1) nula, quando o portal não apresentar indicadores de transparência ativa e/ou impossibilidade de localização dos indicadores no portal; (2) baixa, nos casos de atendimento parcial aos indicadores de 
transparência ativa determinados pela LAl; (3) média, nas situações em que o portal apresentar atendimento de todos os indicadores de transparência ativa exigidos na LAl; e (4) alta, quando o portal apresentar todos os instrumentos de transparência ativa exigidos pela LAI e outros instrumentos de transparência ativa não restritos às exigências legais.

\section{RESULTADOS}

A apresentação dos resultados seguiu a estrutura do modelo de análise. Para tanto, as câmaras foram organizadas em quatro grupos de acordo com a capacidade apresentada pelos portais eletrônicos: portais com nula capacidade, com baixa capacidade, com média capacidade ou com alta capacidade. Após, apresenta-se uma síntese da transparência ativa nas câmaras municipais investigadas.

\subsection{A FALTA DE TRANSPARÊNCIA ATIVA DOS PORTAIS COM NULA CAPACIDADE}

O primeiro grupo contempla os portais de câmaras que apresentaram nula capacidade. Foram classificados neste grupo os portais que não apresentaram indicadores de transparência (exigências legais e/ou não restritos às exigências legais) ou não foi possível localizar tais indicadores nos portais. Do conjunto analisado, 6 (4,51\%) portais foram classificados com nula capacidade, sendo eles: Belford Roxo - RJ; Macapá - AP; Magé - RJ; Mossoró - RN; Paulista - PE; e São Gonçalo - RJ. Mesmo que percentualmente esse grupo não seja representativo, surpreende o fato de que em tais câmaras não foi possível localizar indicadores de transparência. São portais com falta de transparência ativa das ações dos legisladores locais. Cabe recordar que foram considerados apenas os portais de câmaras de municípios com população acima de 200.000 habitantes, ou seja, não se trata de municípios pequenos, sem condições de se ajustar a demanda legal. Além disso, dois municípios estão na região metropolitana do Estado do Rio de Janeiro, outro é a segunda maior cidade do Rio Grande do Norte, um está na região metropolitana de Recife e outro é capital de um Estado (Amapá). Entendendo a presença de Macapá nesta condição, isto indica que mesmo municípios localizados próximos a centros decisórios importantes (as regiões metropolitanas) e Mossoró, que tem expressão econômica relevante, ainda padecem de falta de condições de atendimento à lei.

Duas considerações decorrem dos resultados apresentados neste grupo. Na primeira, se estas câmaras não disponibilizaram indicadores do grupo de exigências legais listados no Quadro 1, no período de observação dos portais, descumpriram às exigências legais de transparência ativa. A segunda, relacionada à primeira, diz respeito ao fato de que estas câmaras não sinalizam a construção de transparência em seu sentido mais amplo (além da exigência legal), visto que nem mesmo o atendimento mínimo, neste caso considerado a Lei, é cumprido.

\subsection{PORTAIS COM BAIXA CAPACIDADE: EVIDÊNCIAS DE CONSTRUÇÃO DE TRANSPAR- ÊNCIA ATIVA?}

Diferentemente do grupo anterior, é representativo o número de portais eletrônicos classificados com baixa capacidade, 120 (90,22\%), mas ainda pertencendo a um nível de baixo desempenho no que diz respeito à transparência. A distribuição dos municípios por regiões e estados é apresentada na Tabela 2. 
Tabela 2: Síntese da transparência ativa nos maiores municípios brasileiros

\begin{tabular}{|c|c|c|c|c|c|c|c|}
\hline \multirow{2}{*}{ Regiões } & \multirow{2}{*}{ Estados } & \multicolumn{5}{|c|}{ Municípios } & \multirow{2}{*}{ Média por Região } \\
\hline & & Nula & Baixa & Média & Alta & Total & \\
\hline \multirow{7}{*}{ Norte } & Pará & 0 & 4 & 0 & 0 & 4 & \multirow{7}{*}{ Baixa } \\
\hline & Roraima & 0 & 1 & 0 & 0 & 1 & \\
\hline & Tocantins & 0 & 1 & 0 & 0 & 1 & \\
\hline & Amazonas & 0 & 1 & 0 & 0 & 1 & \\
\hline & Acre & 0 & 1 & 0 & 0 & 1 & \\
\hline & Amapá & 1 & 0 & 0 & 0 & 1 & \\
\hline & Rondônia & 0 & 1 & 0 & 0 & 1 & \\
\hline \multirow{9}{*}{ Nordeste } & Sergipe & 0 & 1 & 0 & 0 & 1 & \multirow{9}{*}{ Baixa } \\
\hline & Alagoas & 0 & 2 & 0 & 0 & 2 & \\
\hline & Bahia & 0 & 4 & 0 & 1 & 5 & \\
\hline & Paraíba & 0 & 2 & 0 & 0 & 2 & \\
\hline & Pernambuco & 1 & 5 & 0 & 0 & 6 & \\
\hline & Ceará & 0 & 4 & 0 & 0 & 4 & \\
\hline & Rio Grande do Norte & 1 & 2 & 0 & 0 & 3 & \\
\hline & Maranhão & 0 & 2 & 0 & 0 & 2 & \\
\hline & Piauí & 0 & 1 & 0 & 0 & 1 & \\
\hline \multirow{4}{*}{ Centro Oeste } & Goiás & 0 & 3 & 0 & 0 & 3 & \multirow{4}{*}{ Baixa } \\
\hline & Distrito Federal & 0 & 0 & 0 & 1 & 1 & \\
\hline & Mato Grosso & 0 & 2 & 0 & 0 & 2 & \\
\hline & Mato Grosso do Sul & 0 & 1 & 0 & 0 & 1 & \\
\hline \multirow{4}{*}{ Sudeste } & São Paulo & 0 & 38 & 0 & 1 & 39 & \multirow{4}{*}{ Baixa } \\
\hline & Rio de Janeiro & 3 & 10 & 0 & 0 & 13 & \\
\hline & Minas Gerais & 0 & 13 & 0 & 0 & 13 & \\
\hline & Espírito Santo & 0 & 4 & 0 & 0 & 4 & \\
\hline \multirow{3}{*}{ Sul } & Santa Catarina & 0 & 4 & 0 & 0 & 4 & \multirow{3}{*}{ Baixa } \\
\hline & Rio Grande do Sul & 0 & 6 & 0 & 3 & 9 & \\
\hline & Paraná & 0 & 7 & 0 & 1 & 8 & \\
\hline & Total & 6 & 120 & 0 & 7 & 133 & --. \\
\hline
\end{tabular}

Fonte: Dados da pesquisa (2014).

Observa-se que os portais classificados nesta posição se distribuem pelas regiões do Brasil, indicando que a baixa capacidade não é atributo apenas de regiões menos desenvolvidas, mas é encontrada em todas as regiões. A situação é preocupante, pois abarca câmaras até de capitais de Estados importantes (São Paulo, Minas Gerais, Rio de Janeiro e Bahia, por exemplo), bem como um grande número de municípios em regiões metropolitanas mesmo em Estados mais desenvolvidos. Portanto, não se percebe uma relação próxima entre regiões mais desenvolvidas e a manifestação de transparência nos legislativos municipais, mesmo em capitais de estados.

Seguindo o modelo de análise, foram considerados neste grupo os portais em que não foi possível encontrar o total de indicadores decorrentes de exigências legais. Abaixo é apresentada a quantidade e o respectivo percentual de portais eletrônicos que não atenderam a cada um dos indicadores: Registro das competências e estrutura organizacional, endereços e telefones das respectivas unidades e horários de atendimento ao público: 58 (43,60\%); Registros de quaisquer repasses ou transferências de recursos financeiros: 66 (49,62\%); Registros das despesas: 41 (30,82\%); Informações concernentes a procedimentos licitatórios, inclusive os respectivos editais e resultados, bem como a todos os contratos celebrados: 50 (37,59\%); Registro de dados gerais para o acompanhamento de programas, ações, projetos e obras: 16 (12,03\%); Registro das respostas às perguntas mais frequentes: 94 (70,67\%); 
Possibilita qualquer interessado apresentar pedido de informações por meio de formulário eletrônico: 37 (27,81\%); Link específico de transparência que dará acesso às informações de interesso público: 12 (9,02\%); Remuneração e subsídios: 63 (47,36\%); Upload de relatórios em diversos formatos eletrônicos, inclusive abertos, tais como planilhas e texto, de modo a facilitar a análise das informações: 98 (73,68\%).

De forma geral, os indicadores de exigências legais não foram cumpridos por um número representativo de câmaras municipais. Chama atenção o descumprimento para os indicadores registro das respostas às perguntas mais frequentes e upload de relatórios em diversos formatos eletrônicos, inclusive abertos, tais como planilhas e texto, de modo a facilitar a análise das informações, que ficou acima de $70,00 \%$. A relação dos indicadores de transparência ativa restritos às exigências legais ilustra a situação das câmaras pesquisadas em termos de efetividade da LAl, ou seja, em que medida a legislação de transparência ativa é atendida e respeitada pelas câmaras das maiores cidades brasileiras.

Os resultados da aplicação desses indicadores - que representam a adequação ou não dos portais legislativos à legislação de transparência - não são animadores, visto que $45(33,83 \%)$ portais deixaram de apresentar cinco ou mais indicadores, de um total de dez. Por outro lado, 33 (24,81\%) portais eletrônicos não atenderam de um a dois indicadores, o que pode indicar que há uma tentativa de se adequar à lei. Outra evidência de que estes portais possam contribuir para a construção de transparência ativa refere-se ao fato de, mesmo não atendendo à totalidade de exigências legais, em muitos destes portais foram identificados indicadores de transparência não restritos às exigências legais. Entre aqueles que mais deixaram de atender e aqueles que não atenderam a um ou dois indicadores encontram-se 42 $(31,57 \%)$ portais, que não atenderam de três a quatro indicadores. De qualquer forma, o pressuposto de que municípios maiores teriam portais mais estruturados e com razoável atendimento às exigências de disponibilização de informações (Styles \& Tennyson, 2007; Raupp \& Pinho, 2013) não foi confirmado. Merece destaque ainda o fato de que, se no grupo de nula capacidade tem-se apenas 4,51\% dos portais, os resultados aqui se mostram bem desanimadores, pois o grupo de baixa capacidade abarca $90,22 \%$ dos portais. Em outras palavras, se o grupo de nula capacidade for entendido como um desvio está "colado" com o grupo de baixa, indicando que este último domina o conjunto dos portais considerados.

\subsection{A AUSÊNCIA DE PORTAIS COM MÉDIA CAPACIDADE}

Os resultados demonstraram uma inexistência de portais com média capacidade. Isso porque, os portais que apresentaram todos os indicadores restritos às exigências legais, também apresentaram indicadores não restritos às exigências legais. Este cenário pode apresentar os "dois lados da moeda". De um lado, a ausência de média capacidade é decorrência de uma expressiva quantidade de portais com baixa capacidade, demonstrando que a maioria não atende nem mesmo às exigências legais. Sabe-se que algumas exigências da Lei de Acesso à Informação constam no texto da Lei de Responsabilidade Fiscal, de 2000, e da Lei da Transparência, de 2009. Portanto, passados aproximadamente 15 anos, há exigências legais ainda sem cumprimento por parte do legislativo local (Raupp \& Pinho, 2015). Por outro lado, é possível indagar se essas câmaras (que atenderam às exigências legais) estariam preocupadas com a construção de um conceito ampliado de transparência, em que a publicização de informações legais é considerada o "mínimo" a ser atendido. Obviamente, respostas para este questionamento requerem estudos para auscultar a percepção dos legisladores locais, o que não foi objeto do presente estudo. O que esse resultado mostra é que quando se aumenta o nível de exigência, ao sair do baixo para o médio, não há resposta por parte dos portais investigados, o que parece indicar que apenas o 
mínimo, o muito mínimo, está sendo atendido. Se o enquadramento em um nível médio de capacidade de transparência revelaria um alento para a transparência, que estaria assim em construção, isso mostra não acontecer.

\subsection{PORTAIS ELETRÔNICOS COM ALTA CAPACIDADE: HÁ UMA LUZ NO FIM DO} TÚNEL?

O quarto grupo considera os portais eletrônicos classificados com alta capacidade. Foram identificados apenas 7 (5,26\%) portais com esta capacidade, sendo eles: Brasília - DF; Caxias do Sul - RS; Curitiba - PR; Feira de Santana - BA; Gravataí - RS; Jundiaí - SP; Novo Hamburgo - RS. Neste caso já se percebe que a curva tende para a presença de municipalidades de regiões mais desenvolvidas: 4 municípios da região Sul, sendo uma capital; 1 município da região Sudeste, a capital brasileira e 1 município da região Nordeste, não se encontrando nenhum representante da região Norte. A princípio seria de se esperar que todas as capitais, ou uma boa parte delas, estivessem aqui, mas isso não se concretizou, com as câmaras das capitais ocupando os níveis mais rasteiros da escala de transparência, o que é seguramente desalentador. A exigência para alta capacidade corresponde ao atendimento integral aos indicadores legais de transparência e disponibilização de indicadores de transparência não restritos às exigências legais. Mesmo não exigindo o atendimento integral aos indicadores não restritos às exigências legais, três municípios apresentaram essa configuração: Brasília - DF; Gravataí - RS; Jundiaí - SP.

Ressalta-se que outros municípios atenderam integralmente aos indicadores não restritos às exigências legais, porém, descumpriram indicadores de exigência legal: Americana - SP; Belo Horizonte - MG; Fortaleza - CE; Ipatinga - MG; Juiz de Fora - MG; Limeira - SP; Londrina - PR; Maringá - PR; Osasco - SP; Piracicaba - SP; Rio de Janeiro - RJ; Santos - SP; São José - SC; São Paulo - SP; Serra - ES; e Vitória - ES. Destes, Americana - SP, São José - SC, São Paulo - SP, e Serra - ES, descumpriram apenas um indicador de exigência legal. Esta categoria de indicadores, apesar de não serem exigências legais, são instrumentos estratégicos que aperfeiçoam a troca de informações com maior grau de velocidade, precisão e envolvimento dos cidadãos. Portais eletrônicos que atendem às exigências legais e somam à sua arquitetura ferramentas estratégicas, possuem um grau mais elevado de relevância social e política, pois, além do acesso às informações, possibilitam a interoperabilidade, a prestação de serviços on-line e a interação e colaboração entre cidadão e administração pública (Terra \& Gordon, 2002; Ruediger, 2002; Fountain, 2005; Pinho, 2008). Um diagnóstico mais preciso sobre esta situação, aparentemente paradoxal, exigiria um estudo mais aprofundado, mas os resultados parecem mostrar que atender ao disposto na Lei mostra-se difícil de ser atingido. Por outro lado, sendo otimista, o atendimento de demandas não fixadas em lei pode indicar que existe uma predisposição de câmaras na construção de transparência.

\section{CONCLUSÕES}

O artigo apresentou os resultados do estudo que teve por objetivo investigar a transparência ativa de câmaras localizadas em municípios brasileiros com população superior a duzentos mil habitantes a partir de evidências empíricas dos portais eletrônicos. As câmaras foram organizadas em quatro grupos de acordo com a capacidade apresentada pelos portais eletrônicos: portais com nula capacidade, com baixa capacidade, com média capacidade ou com alta capacidade. Apesar da tentativa de agrupar os portais em quatro categorias, observou-se a presença de outras possíveis categorias que futuramente 
poderão fazer parte de um novo modelo de análise, considerando portais que não atendem integralmente às exigências legais, porém, apresentam alguns indicadores não restritos às exigências legais. A aplicação do modelo de análise em relação aos indicadores de instrumentos de transparência não restritos às exigências legais pode representar instrumentos estratégicos que, além de possibilitar o acesso às informações relevantes para o controle social, também, otimizam o processo de pesquisa, análise e interpretação. São instrumentos que contribuem para a construção de um portal mais accountable. Dito de outra forma, ao se deixar a sociedade falar, pode ser que esta expresse outros tipos de demandas aos legislativos municipais que não estão sendo cobertos pelas leis e nem pela formulação teórica.

A escolha por municípios com população superior a duzentos mil habitantes pressupunha resultados mais animadores, já que se estava circunscrito a um universo onde o desenvolvimento e a modernidade se fazem mais presentes, o que se pressupunha também incluir uma sociedade civil mais ativa e legislativos mais sintonizados com as imposições da lei. Contudo, revelaram os resultados que a maioria dos portais, 120 (90,22\%), não atende nem mesmo aquilo que se considera como "mínimo": a exigência legal. Mesmo não sendo um resultado muito expressivo, surpreende que $6(4,51 \%)$ não tenham apresentado nenhum indicador de transparência ativa, conferindo a estes portais a nula capacidade. Como práticas possivelmente exitosas e que poderiam ser seguidas pelos demais legislativos, foram identificados 7 $(5,26 \%)$ portais com alta capacidade. Os resultados contribuem para um diagnóstico situacional dos portais eletrônicos em relação à adequação ou não desses instrumentos à legislação, bem como da presença de outros indicadores que ampliam o conceito de transparência. Resgatando o diálogo com a teoria, parece que continua nos faltando o conceito de accountability e uma de suas expressões, a transparência. Isto serve para nos posicionar no tocante as possibilidades da tecnologia. Ainda que esta esteja disponível e avance aceleradamente ela não mostra condições de dissolver processos políticos e sociais enraizados na sociedade brasileira, como o patrimonialismo. Mostra também como esses processos são não só resistentes aos imperativos da tecnologia, mas também da própria lei ou leis. De qualquer forma, tudo se move, e os avanços serão, ao que tudo indica, lentos na realidade brasileira.

\section{REFERÊNCIAS}

Akutsu, L., \&Pinho, J. A. G. de. (2002). Sociedade da informação, accountability e democracia delegativa: investigação em portais de governo no Brasil. Revista de Administração Pública, 36(5), 723-745.

Angélico, F. (2012). Lei de Acesso à Informação Pública e seus possíveis desdobramentos à accountability democrática no brasil. Dissertação (Mestrado) - Curso de Administração Pública e Governo, Escola de Administração de Empresas de São Paulo, São Paulo.

Arato, A. (2002). Representação, soberania popular e accountability. Lua Nova, 55-56, 85-103.

Babbie, E. (1999). Métodos de pesquisas de survey. Belo Horizonte: UFMG.

Bairral, M. A. da C., Silva, A. H. C., \&Alves, F. J. dos S. (2015). Transparência no setor público: uma análise dos relatórios de gestão anuais de entidades públicas federais no ano de 2010. Revista de Administração Pública, 49(3), 643-675.

Bass, G. D., \& Moulton, S. (2010). Bringing the Web 2.0 revolution to government. In: LATHROP, D.; RUMA, L. Open government: collaboration, transparency, and participation in practice.Sebastopol: O'Reilly Media. 
Bass, G. D., \& Moulton, S. (2010). Bringing the Web 2.0 revolution to government. In: LATHROP, D.; RUMA, L. Open government: collaboration, transparency, and participation in practice.Sebastopol: O'Reilly Media.

Barbosa, A. F. (Coord.). (2014). Pesquisa sobre o uso das tecnologias da informação e comunicação no setor público brasileiro: TIC Governo Eletrônico 2013. São Paulo: Comitê Gestor da Internet no Brasil.

Brasil. (1988). Constituição da República Federativa do Brasil. Brasília.

Brasil. (2000). Lei de Responsabilidade Fiscal. Lei Complementar n 101, de 04 de maio de 2000. Presidência da República. Casa Civil. Subchefia para Assuntos Jurídicos. Brasília.

Brasil. (2009). Lei da Transparência. Lei Complementar n 131, de 27 de maio de 2009. Presidência da República. Casa Civil. Subchefia para Assuntos Jurídicos. Brasília.

Brasil. (2011). Lei de Acesso à Informação. Lei n 12.527, de 18de novembro de 2011. Presidência da República. Casa Civil. Subchefia para Assuntos Jurídicos. Brasília.

Brasil. (2012). Decreto n 7.724, de 16 de maio de 2012. Presidência da República. Casa Civil. Subchefia para Assuntos Jurídicos. Brasília.

Campos, A. M. (1990). Accountability: quando poderemos traduzi-la para o português? Revista de Administração Pública, 24(2), 30-50.

Creswell, J.W. (2007). Projeto de pesquisa: método qualitativo, quantitativo e misto. Porto Alegre: Artmed.

Denhardt, J. V., \& Denhardt, R.B. (2007).The new public service: serving, not steering. Expanded Edition. New York: M. E. Sharpe, Inc.

Denhardt, R. B. (2012). Teorias da administração pública. São Paulo: Cengage.

Dias, C. A. (2001). Portal corporativo: conceitos e características. Ci. Inf., 30(1), 50-60.

Diniz, E. H. et al. (2009). O governo eletrônico no Brasil: perspectiva histórica a partir de um modelo estruturado de análise. Revista de Administração Pública, 43(1), 23-48.

Ferreira, F. B. et al. (2014). Monitoramento da Lei de Acesso à informação pública em 2013. São Paulo: Mooa Estúdio.

Fountain, J. E. (2001).Building the virtual state: information, technology and institutional change. Washington, D.C: Bookings Institution Press.

Fountain, J. E. (2005). Construindo um estado virtual: tecnologia da informação e mudança institucional. Brasília: Enap.

Fung, A., \& Weil, D. (2010). Open government and open society. In: Lathrop, D., Ruma, L. Open government: collaboration, transparency, and participation in practice. Sebastopol: O'Reilly Media.

Gil, A. C. (2002). Como elaborar projetos de pesquisa. São Paulo: Atlas.

Instituto Brasileiro de Geografia e Estatística - IBGE. (2013). Censo demográfico 2010. 2010. Disponível em: <http://www.ibge.gov.br/>.

Jordão, R. (2011). Acesso à informação pública: uma introdução à Lei 12.527, de 18 de novembro de 2011. Brasília: Eclips Design.

Koppell, J. G. S. (2005). Pathologies of accountability: ICANN and the Challenge of "Multiple Accountabilities Disorder". Public Administration Review, 65(1), 94-108. 
Michener, G., \& Bersch, K. (2011). Conceptualizing the quality of transparency. In: 1st Global Conference on Transparency Research, 2011, Newark. Proceedings of 1st Global Conference on Transparency Research.Newark: University of Rutgers.

Noveck, B. S. (2009).Wiki government: how technology can make government better, democracy stronger, and citizens more powerful. Washington, D.C.: Brookings Institution Press.

Pinho, J. A. G. de. (2008). Investigando portais de governo eletrônico de estados no Brasil: muita tecnologia, pouca democracia. Revista de Administração Pública, 42(3), 471- 493.

Pinho, J. A. G. de, \&Sacramento, A. R. (2009). Accountability: já podemos traduzi-la para o português? Revista de Administração Pública, 43(6), 1343-1368.

Prado, O. Governo eletrônico e transparência: a publicização das contas públicas das capitais brasileiras. 2004. 180 p. Dissertação (Mestrado em Administração Pública e Governo) - Escola de Administração de Empresas de São Paulo da Fundação Getúlio Vargas, São Paulo, 2004.

Prado, E. P. V. et al. (2011). Iniciativas de governo eletrônico: análise das relações entre nível de governo e características dos projetos em casos de sucesso. Revista Eletrônica de Sistemas de Informação, 10(1), $1-22$.

Raupp, F. M. (2011). Construindo a accountability em câmaras municipais do estado de Santa Catarina: uma investigação nos portais eletrônicos. Tese (Doutorado) - Curso de Administração, Universidade Federal da Bahia, Salvador.

Raupp, F. M., \& Pinho, J. A. G. de. (2013). Os vereadores prestam contas em portais eletrônicos? um estudo comparativo entre municípios do estado da Bahia e de Santa Catarina. Administração Pública e Gestão Social, 5(3), 89-97.

Raupp, F. M., \& Pinho, J. A. G. de. (2015). Prestação de contas no legislativo local antes e depois da Lei de Acesso à Informação. ConTexto, 15(29), 30-46.

Ruediger, M. A. (2002). Governo eletrônico e democracia: Uma análise preliminar dos impactos e potencialidades na gestão pública. Organizações \& Sociedade, 9(25), 29-43.

Santos, P. M., Bernardes, M. B., \& Rover, A. J. (2012). Teoria e prática de governo aberto: Lei de Acesso à Informação nos executivos municipais da região sul. Florianópolis: Fundação Boiteux.

Schedler, A., Diamond, J. L., \& Plattner, F. M. (1999). The self-restraining state: power and accountability in new democracies. London: Lynne Rienner.

Strathern, M. (1999). A explosão das avaliações no sistema universitário. Novos Estudos, 53, 15-31.

Styles, A. K., \& Tennyson, M. (2007). The accessibility of financial reporting of U.S. municipalities on the Internet. Journal of Public Budgeting, Accounting \& Financial Management, 19(1), 56-92.

Swartz, A. (2010). When is transparency useful. In: Lathrop, D., \& Ruma, L. Open government: collaboration, transparency, and participation in practice. Sebastopol: O'Reilly Media.

Terra, J. C. C., \& Gordon, C. (2002). Portais corporativos: a revolução na gestão do conhecimento. São Paulo: Negócio Editora.

Vianna, L. W. (1999). Weber e a interpretação do Brasil. Novos Estudos, 53, 33-47. 